\title{
MEMÓRIAS
}

MULHERES SERINGUEI NA RESERVA EXTRATIV RIO OURO PRETO/ LINGUAGEM, CULT E IDENTID 


\section{MEMÓRIAS DE MULHERES SERINGUEIRAS NA RESERVA EXTRATIVISTA RIO OURO PRETO/RO: LINGUAGEM, CULTURA E IDENTIDADE}

\section{EVA DA SILVA A LVES}




\section{MEMÓRIAS DE MULHERES SERINGUEIRAS NA RESERVA EX- TRATIVISTA RIO OURO PRETO/RO: LINGUAGEM, CULTURA E IDENTIDADE}

\section{Resumo}

Este trabalho apresenta o registro, a descrição e a análise de aspectos da linguagem das mulheres seringueiras e agroextrativistas da Reserva Extrativista Rio Ouro Preto (RESEX) em Guajará-Mi$\mathrm{rim} / \mathrm{RO}$, evidenciando marcas identitárias culturais e mostrando, a partir das histórias de vida, que esse grupo possui um léxico específico, permeado por elementos constituidores de identidade, misticismo e subjetividade. Trata-se de um estudo sociolinguístico, de cunho etnográfico, no qual foram entrevistadas mulheres que residem na referida RESEX. Verifica-se, nas narrativas orais registradas e analisadas, que a linguagem desse grupo reflete marcas identitárias linguísticas e socioculturais que expressam saberes singulares.

Palavras-chave: Cultura. Mulheres. Seringais.

\section{MEMOIRES DE FEMMES TRAVAILLANT EN CAOUTCHOUC DANS LA RESERVE RIO OURO PRETO/RO : LANGAGE, CUL- TURE ET IDENTITE}

\section{Résumé}

Cet article présente l'enregistrement, la description et l'analyse d'aspects du langage des femmes travaillant en caoutchouc et agroextractivistes de la réserve d'extraction Rio Ouro Preto (RESEX) à Guajará-Mirim/RO, mettant en évidence des identités culturelles et montrant, à partir des histoires de vie, que ce groupe possède un lexique spécifique, pénétré par des éléments qui constituent l'identité, le mysticisme et la subjectivité. Il s'agit d'une étude sociolinguistique, de caractère ethnographique, dans laquelle les femmes qui habitent dans la RESEX ont été interviewées. Il est vérifié, dans les récits oraux enregistrés et analysés, que le langage de ce groupe reflète des marques d'identité linguistiques et socioculturelles qui expriment des savoirs singuliers.

Mots-clés: Culture. Femmes. Caoutchouc. 


\title{
MEMORIES OF RUBBER WOMEN AT THE RIO OURO PRETO/ RO EXTRACTICE RESERVE: LANGUAGE, CULTURE AND IDEN- TITY
}

\begin{abstract}
This paper presents the registration, description and analysis of aspects of the language of rubber and agroextractivist women of the Rio Ouro Preto Extractive Reserve (RESEX) in Guajará-Mirim/RO, evidencing cultural identity marks and showing from life stories that this group has a specific lexicon, permeated by elements that constitute identity, mysticism and subjectivity. It is an ethnographic sociolinguistic study in which women residing in the RESEX were interviewed. It is verified, in the oral narratives recorded and analyzed, that the language of this group reflects linguistic and sociocultural identity marks that express singular knowledge.
\end{abstract}

Keywords: Culture. Women. Rubber.

Eva da Silva Alves

evaalvesgm@yahoo.com

Auxiliadora dos Santos Pinto

auxipinto@hotmail.com

Renato Fernandes Caetano

renatusfc@hotmail.com 


\section{INTRODUÇÃO}

Este trabalho apresenta, a partir da reconstituição de memórias e de histórias de vidas, um breve registro, descrição e análise da linguagem de mulheres seringueiras e agroextrativistas, evidenciando marcas identitárias sócio-históricas, culturais e linguísticas. Trata-se de um estudo, preliminar, desenvolvido nas comunidades da Reserva Extrativista Rio Ouro Preto (RESEX) em Guajará-Mirim/RO, no período de janeiro de 2013 a novembro de 2014. Essas comunidades compõem um ecossistema multicultural e plurilinguístico. Nesse sentido, observa-se que as mulheres participantes da pesquisa são descendentes de indígenas, nordestinos, bolivianos e remanescentes de quilombos. Elas fazem parte de um grupo estigmatizado, por pertencerem a uma classe menos prestigiada social e linguisticamente, considerando que muitas não são alfabetizadas e viveram grande parte de suas vidas nos contextos dos seringais.

Para atingir o objetivo proposto, estabeleceu-se os seguintes objetivos específicos: registrar, a partir das narrativas orais e da reconstituição das memórias, as histórias de vida de mulheres seringueiras e agroextrativistas que viveram/vivem na RESEX Rio Ouro Preto; reconstituir, a partir da linguagem memorática, práticas e saberes de mulheres seringueiras e agroextrativistas da referida reserva; refletir sobre os sentidos dos fatos históricos e sociais narrados pelas mulheres seringueiras e agroextrativistas, destacando a importância das fontes orais para a preservação da história, da cultura e da identidade feminina na referida reserva; investigar se o papel social desempenhado pelas mulheres seringueiras e agroextrativistas das referidas comunidades estão sendo modificados ao longo dos anos ou se as narrativas orais evidenciam, ainda, um discurso permeado por elementos que demonstram a submissão e a degradação social da mulher.

A relevância do estudo sobre essa temática justifica-se a partir de dois aspectos: o social e o científico, abaixo descritos:

No aspecto pessoal, o estudo desse tema é relevante no aspecto social porque além de destacar o papel social e as dificuldades enfrentadas pelas mulheres que trabalharam/trabalham nos seringais, em plena selva amazônica, em busca de sobrevivência e sustento da família, também proporcionará discussões e reflexões sobre o papel social que as mulheres seringueiras desempenham, atualmente, nas comunidades que compõem a RESEX Rio Ouro Preto.

No aspecto científico, a pesquisa é relevante porque possibilita o estudo dos fatores que contribuíram para a constituição da cultura, da linguagem e da subjetividade da mulher seringueira e, consequentemente, para o registro dos falares que compõem o ecossistema linguístico do município de Guajará-Mirim/RO.

O problema de pesquisa foi norteado pelos seguintes questionamentos: quais os principais elementos constituidores da linguagem, da cultura e da identidade das mulheres seringueiras e agroex- 
trativistas da RESEX Rio Ouro Preto? Quais os elementos que evidenciam a subjetividade e o misticismo nos discursos das mulheres seringueiras e agroextrativistas? Como são construídos os sentidos dos fatos históricos e sociais que contribuem/contribuíram para a constituição da identidade feminina na RESEX Rio Ouro Preto?

O trabalho foi fundamentado pelas matrizes teóricas que discutem as seguintes temáticas: história, linguagem, cultura, memória e identidade, destacando-se os estudos de Loureiro (1995 - 1998), que caracteriza, de forma detalhada, a cultura amazônica e as múltiplas representações dos sujeitos amazônicos; Tedeschi (2010), cujos estudos discutem sobre limites de gênero e memórias de mulheres agricultoras, destacando a luta dessas mulheres por seus direitos sociais; Nascimento (1996), que descreve o espaço ribeirinho e o trabalho das mulheres nos seringais da Amazônia; Wolf (2011), que discute sobre a presença feminina no contexto dos seringais da Amazônia e Simonian (2001) que traz evidencias da presença feminina nos contextos amazônicos desde antes do grande boom da borracha; Beauvoir (1949) que questiona a posição de inferioridade que foi imposta às mulheres por séculos; Teixeira \& Fonseca (2002), cujos trabalhos registram a história das comunidades tradicionais da Amazônia, enfocando os ciclos da borracha e a participação das mulheres nos seringais; Laraia (1986), o qual apresenta conceitos antropológicos de cultura; Delgado (2006), que descreve os processos de constituição da memória, destacando que História,
Tempo, Memória e Identidades são processos inter-relacionados e outros.

A análise dos dados foi realizada em consonância com os princípios teóricos e metodológicos da Pesquisa Sociolinguística, proposta por Mollica (2003), que apresenta os fatores internos/externos da variação linguística e pelos estudos culturais amazônicos propostos por Loureiro (1995- 1998) e outros.

Dessa forma, pretende-se, com o desenvolvimento dessa pesquisa, valorizar os elementos constituidores da cultura, da identidade e da subjetividade feminina nos seringais da RESEX Rio Ouro Preto, contribuindo, também, para o registro dos falares que compõem o ecossistema linguístico e sociocultural do município de Guajará-Mirim/RO.

\section{O PROCESSO DE OCUPAÇÃO DA REGIÃO GUAJARAMIRENSE: AL- GUNS ASPECTOS}

Segundo os historiadores Oliveira (2004) e Teixeira \& Fonseca (2001), o município de Guajará-Mirim/RO constituiu-se como cidade após vários processos de ocupação que datam desde o século XVIII. Consta ainda que, por volta de 1723, estiveram nessas terras quatro expedições que objetivaram a exploração das riquezas da região. Naquela época, sob os desígnios da Coroa Portuguesa, foram fundadas aldeias, que foram ocupadas pelas missões religiosas a fim de catequizar os índios e capitanias para concretizar a "[...] a intensa política de povoamento 
dos vales do Guaporé, Mamoré e Madeira até a localidade de Santo Antônio". (Oliveira 2004:16). No final do século XIX, após anos de abandono, a região passou por outro processo de ocupação, desta vez por ocasião do Primeiro Ciclo da Borracha (18871912). Com isso, a região “[...] recebeu um grande contingente de nordestinos, principalmente cearenses, que subiram esses rios à procura de trabalho nos seringais". (Oliveira 2004: 27).

A mão de obra nos seringais também teve a participação dos indígenas que, muitas vezes, eram escravizados de forma deliberada. Além disso, os seringalistas ordenavam invasões a terras indígenas, resultando em violentos embates entre indígenas e não indígenas. Nesse contexto, depois de inúmeras tentativas e conflitos na ocupação da Amazônia, em 1903, o governo brasileiro assinou o Tratado de Petrópolis, cujo objetivo principal era a construção de uma estrada de ferro para o transporte da borracha produzida na fronteira Brasil/Bolívia.

Em 1907, teve início a construção da Estrada de Ferro Madeira Mamoré (EFMM). A ferrovia ligava a região, onde atualmente é a capital do Estado, Porto Velho, até a fronteira boliviana, onde atualmente, localiza-se o município de Guajará-Mirim. O empreendimento contou com a mão de obra de “[...] aproximadamente 21.817 operários, provenientes de diversas nacionalidades" (Oliveira 2004:53). Dadas as dificuldades de sobrevivência na floresta inóspita e insalubre, muitos operários morreram em consequência das doenças tropicais, ataques de animais silvestres e embates com os indígenas que habitavam a região.

A construção da EFMM foi concluída somente em 1912. No entanto, naquela época, o Brasil deixara de ser o único a produzir a borracha, com isso, a queda de preço do produto foi inevitável e a produção diminuiu drasticamente. Assim, a ferrovia perdeu a importância, tornando-se forçoso o abandono dos seringais por boa parte dos seringueiros.

Após alguns anos de decadência, na década de 1940, por ocasião da Segunda Guerra Mundial, a região voltou a ser explorada, pois os japoneses tomaram os seringais da Malásia e, necessitados da matéria prima para a produção de pneus e outros artefatos para utilização nos campos de batalha, os Estados Unidos da América (EUA) voltaram a ter interesse nos seringais da Amazônia brasileira, o que deu início ao Segundo Ciclo da Borracha.

No ano de 1942, os Estados Unidos da América firmaram com o Brasil os "famosos" Acordos de Washington, cujo objetivo principal era o financiamento da mão de obra nos seringais visando "[...] o aumento da produção da borracha amazônica e seu fornecimento às indústrias norte-americanas". (Teixeira 2001:158).

Assim, para cumprir os compromissos assumidos com os Estados Unidos da América, o governo brasileiro contratou homens de diversos lugares do país, em sua maioria nordestinos, para tralharem nos seringais e suprir a demanda de produção de borracha. Naquela ocasião, muitos homens vie- 
ram para a Amazônia encaminhados pelo governo. Outros, motivados pelas propagandas "enganosas", vieram por conta própria, pois os jornais da época e emissoras de rádio noticiavam quão lucrativo negócio o governo oferecia. Para Teixeira \& Fonseca, esses recrutamentos tiveram resultados catastróficos. Quanto ao número de homens trazidos, os autores relatam que:

“[...] em uma relação de 1942, elaborada pela SEMTA há um total 4.050 trabalhadores enviados para a Amazônia. Desse total 1.013 (25,01\%) foram envidados para diversas localidades do rio Madeira [...] Com base em depoimentos dados ao Conselho Nacional após a guerra, estimou-se que durante o período migraram para a Amazônia 52.000 pessoas [...]." (Teixeira \& Fonseca 2003:160).

Neste cenário, o Segundo Ciclo da Borracha constituiu-se como um acontecimento muito importante para a revitalização dos vales do Madeira, Mamoré e Guaporé, principalmente, para o município de Guajará-Mirim e para o atual estado de Rondônia, pois a partir desses acontecimentos formaram-se vários núcleos de povoamento que aos poucos foram elevados à categoria de municípios e, atualmente, compõem o Estado de Rondônia.

\section{A REALIDADE NOS SERINGAIS DA AMAZÔNIA}

Os homens que migraram para a Amazônia para trabalharem nos seringais esperavam encontrar um lugar próspero, farto, onde fossem acolhidos com respeito e pudessem viver com dignidade. No entanto, os ditos "Soldados da Borracha" foram ludibriados pelo Governo Federal e, conforme relata Cunha (1967:5), “[...] antes de seguir para a barraca, no centro, que o patrão lhe designara. Ainda é um brabo, isto é, ainda não aprendeu o corte da madeira e já deve 1:135\$000. Segue para o porto solitário [...]". Esse valor lhes era entregue em forma de mantimentos, que duravam em média três meses: utensílios básicos de cozinha, uma espingarda, cartuchos e uma rede.

Abandonados à própria sorte nas colocações dos seringais, esses homens enfrentaram a mata fechada, a fome, as doenças tropicais, os confrontos com índios, que não queriam ter suas terras invadidas e a humilhação por parte da maioria dos patrões, pois eram submetidos às regras impostas pelos proprietários dos barracões e, dependiam da visita dos comboieiros para adquirir gêneros alimentícios no sistema de aviamento. Pois muitos seringueiros levavam até cerca de um ano para ir à cidade.

Eles eram proibidos de plantar, caçar e pescar, para não se atrapalharem na extração do látex e para permitirem ao patrão maior lucratividade no fornecimento dos gêneros alimentícios. Não obstante, não tinham direito a descanso semanal ou feriado, trabalhavam ininterruptamente semana a semana. No período das secas eles trabalhavam duramente; porém, no período das cheias, as terras alagavam e os seringueiros ficavam desolados. Como precisavam se alimentar, endividavam-se cada vez mais. Além de todos esses so- 
frimentos, os seringueiros, na maioria muito jovens, também eram privados de constituir famílias, pois na região haviam poucas mulheres.

\section{A PRESENÇA FEMININA NOS SE- RINGAIS}

De acordo com Simonian (2001:80), embora haja poucos registros acerca da presença feminina e dos trabalhos por elas desenvolvidos no contexto dos seringais amazônicos, o número de relatos acerca dos abusos sofridos por mulheres indígenas e não indígenas nos séculos XIX e XX evidenciam que elas fizeram parte do processo de ocupação da região amazonense, acreana e rondoniense, contribuindo diretamente para a exploração e produção da borracha nos seringais da região, bem como de outras regiões amazônicas.

Conforme relata Wolff (2011:29)., "As mulheres perfaziam aproximadamente $25 \%$ da população não indígena do Alto Juruá, na época implantação do Território Federal." (2011: 30), isso em 1904, durante o boom da borracha. Com relação à região amazonense, Wolff afirma que "[...] as famílias fugiam juntas da seca e da miséria do sertão nordestino e costumavam ficar em lugares próximos de Manaus ou de outra cidade."

Assim como em outros seringais da Amazônia brasileira, a população do seringal do Rio Ouro Preto, inicialmente, era formada basicamente por homens, mas, aos poucos, com a queda do preço da borracha, após a Segunda Guerra Mundial, os seringalistas passa- ram a permitir a entrada das mulheres nos seringais para evitar o êxodo dos seringueiros. Naquela época, haviam muitas reclamações com relação à distância da família e à falta de mulheres nos seringais.

A presença humana na Amazônia rondoniense com o objetivo da extração do látex remota o final do século XIX (Santos 2014:32). No entanto, vale ressaltar que somente no Segundo Ciclo da Borracha há registros da presença de mulheres nos seringais. Contudo estes registros se ressumem a poucas palavras que dão à mulher o papel de protagonistas da história, pois são mencionadas de forma discreta, ou seja, quando se fala sobre o "seringueiro" às vezes aparece palavra família, o que pressupõe-se a presença de uma mulher.

Atualmente, na RESEX do Rio Ouro Preto vivem mulheres que, segundo dados obtidos durante as entrevistas, vieram de antigos seringais que ficavam nas regiões de São Miguel do Guaporé, do rio Cautário e do município de Costa Marques e do distrito de Surpresa, ou são nascidas na reserva. Assim, as comunidades da RESEX Rio Ouro Preto são bem diversificadas cultural e linguisticamente, formadas por um processo de miscigenação.

\section{ASPECTOS HISTÓRICO-GEOGRÁFI- COS DA RESEX RIO OURO PRETO}

Após muitos embates com grileiros, madeireiros e discussões políticas em defesa da preservação da Floresta Amazônica e dos direitos pela posse 
da terra na qual habitavam, em 1985, seringueiros do Acre e Rondônia se reuniram com políticos no Congresso Nacional, em Brasília. Após esse encontro, o movimento em prol da reforma agrária dos seringueiros ganhou força. O movimento foi liderado pelo seringueiro acreano Chico Mendes, que, naquela época, era um importante líder sindical. O ponto culminante dessa luta foi o assassinato desse sindicalista, no ano de 1988, pois esse fato teve repercussão internacional e forçou o governo brasileiro a se posicionar. Assim, “[...] em 1989, as Reservas Extrativistas foram legitimadas, no âmbito da Política Nacional do Meio Ambiente, possibilitando sua criação a partir da Lei 7.804/1989 e sua regulamentação através do Decreto 98.897/1990."

A RESEX Rio Ouro Preto, lócus da pesquisa, foi criada pelo Decreto $\mathrm{N}^{\circ}$. 99.166, de 13 de março de 1990. Até o ano 2007 ela era coordenada pelo Instituto Brasileiro do Meio Ambiente e dos Recursos Naturais Renováveis
(IBAMA). Atualmente, a RESEX é coordenada pelo Instituto Chico Mendes de Conservação da Biodiversidade (ICMBIO), órgão que é responsável pela manutenção de todas as Unidades de Conservação (UCs).

A RESEX Rio Ouro Preto, atualmente, é dividida em duas partes e é formada pelas comunidades do Alto Rio Ouro Preto e pelas comunidades do Baixo Rio Ouro Preto. Além disso, também possui localidades terrestres. A parte do Alto Rio Ouro Preto é constituída por sete comunidades, que são ocupadas, aproximadamente, por sessenta e cinco famílias. Essas comunidades são coordenadas pela Associação dos Seringueiros da Reserva Extrativista do Rio Ouro Preto (ASROP), cujo presidente, à época da pesquisa, era o Sr. José Avilhaneda Amutari. A RESEX conta também com a Associação de Mulheres Agroextrativista de Guajará-Mirim (ASMAGM), que tem como presidenta a Sra. Angélica Casimiro dos Santos.

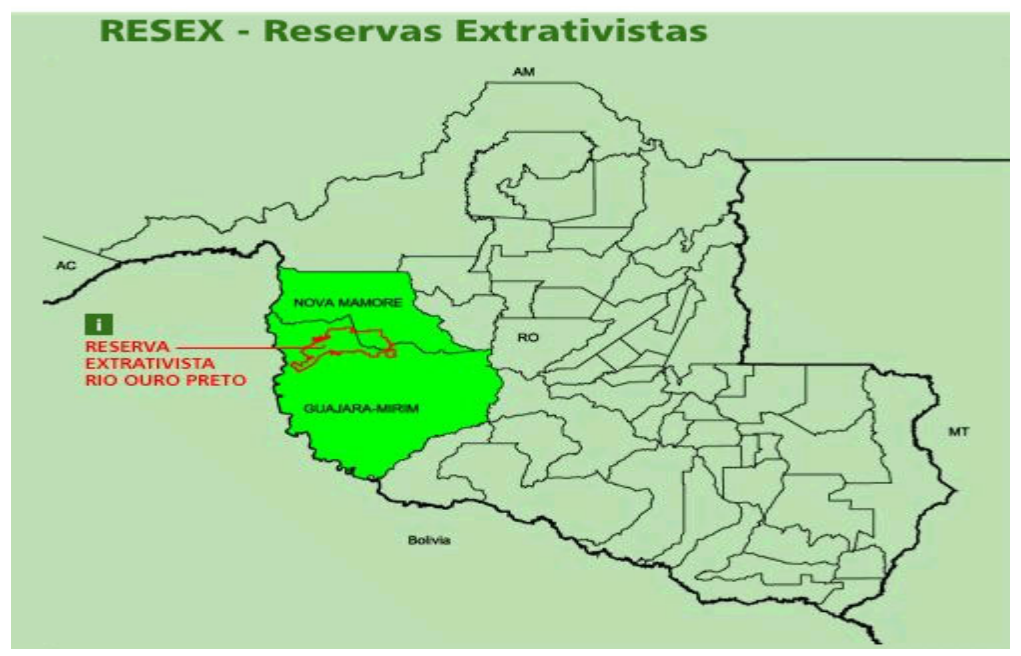

Figura 1 - Mapa da RESEX Rio Ouro Preto. Fonte: Site do ICMbio. 
As sete comunidades visitadas, durante a realização desta pesquisa, contam apenas com um posto de saúde. Porém, observou-se que não há recursos materiais básicos para os tratamentos essenciais. Os moradores recebem, mensalmente, a visita de dois agentes de saúde que distribuem cloro e dão orientações com relação à higiene básica como, por exemplo, a utilização de fossas, o tratamento da água antes de ser consumida, além da prevenção de doenças tropicais, como a malária e a dengue.

Ao lado do posto de saúde, que se localiza na comunidade Sapezal, há uma Escola de Ensino Fundamental que atende aos alunos das comunidades do Alto Rio Ouro Preto. Além do contrato com a prefeitura para ministrar aulas às crianças, a professora participa do projeto de Alfabetização de Jovens e Adultos. Nesse contexto, por ser a única escola existente nessa parte da RESEX, os pais deixam suas colocações e passam, praticamente, todo o ano letivo nessa comunidade.

Aos domingos, pela manhã, o presidente da ASROP e a presidente da ASMAGM, apresentam, na Rádio Educadora, em Guajará-Mirim/RO, um programa radiofônico intitulado "Bom dia seringueiro". Nesse programa, além de serem veiculados avisos diversos, são discutidas questões relacionadas às políticas públicas importantes para as comunidades da RESEX, tais como: projetos de utilização dos recursos retirados da floresta, financiamento de verbas para reforma da escola, do posto de saúde, dentre outras questões como a merenda escolar, medicamen- tos e outros.

Os extrativistas seguem ainda um código de uso da reserva, denominado "Plano de Utilização". O documento foi elaborado em consonância com os interesses do IBAMA e dos moradores, redigido de acordo com a linguagem dos mesmos, para facilitar a compreensão. "A Comissão das Populações Tradicionais do IBAMA, que aprovou este Texto, procurou mantê-lo no linguajar original em que foi escrito pelos moradores da Reserva." As diretrizes variam desde a utilização da terra até mesmo a entrada de pessoas na Reserva. Nesse sentido, os moradores da RESEX do Rio Ouro Preto também assumem o papel de fiscais voluntários. Em caso de desobediência a qualquer cláusula destas diretrizes, o morador pode perder a Licença de Uso, ficando impedido, até mesmo de morar na reserva.

\section{A PESQUISA}

A seguir, apresenta-se uma breve descrição dos procedimentos metodológicos da pesquisa, detalhando cada uma das etapas desenvolvidas. De acordo com os pressupostos da História Oral, o momento de pesquisa in loco é crucial para a compreensão do objeto de pesquisa, uma vez que fora de seu ambiente e, dependendo da forma como é abordado, o entrevistado tende a fazer monitoramento do seu repertório linguístico. Nesse sentido, destaca-se que o assunto abordado durante as entrevistas foi tratado de maneira sutil para que as informantes se sentissem à vontade para agir naturalmente. 
Como afirma Mollica (2003) "[...] os falantes possuem um repertório linguístico que pode variar dependendo de onde se encontram e com quem fala". Além disso, as interações sociais com as entrevistadas e com o contexto da pesquisa favoreceu a coleta de dados, tornando o trabalho mais produtivo.

\section{AS ESCOLHAS TEÓRICO-METODO- LÓGICAS}

A pesquisa bibliográfica e de campo, do tipo qualitativa e de natureza etnográfica, foi norteada pelos pressupostos da Sociolinguística Varacionista, pelos estudos da Cultura Amazônica e pela História Oral. Nesta concepção, observar as comunidades tradicionais como detentoras de um conhecimento singular, galgado a partir das experiências vividas é, em certa medida, valorizar a riqueza de suas práticas e dos papeis sociais, respeitando a individualidade e identidade de cada um. Nessa perspectiva, Delgado afirma que "O passado apresenta-se como vidro estilhaçado de um vitral antes composto por inúmeras cores e partes". (2006:34). Assim, a reconstituição das histórias de vidas é recurso indispensável para a compreensão da constituição dos sujeitos, pois trabalhar com o discurso produzido por mulheres a partir da reconstituição de suas memórias, conforme afirma Tedeschi (2010:179): “[...] é uma revanche com relação à história tradicional, pois possibilita a reconstituição da história trazendo à tona as desigualdades de gênero". Nesta pesquisa, as narrativas orais foram elementos eficazes para se identificar aspectos culturais, que perfazem os caminhos percorridos pelas mulheres entrevistadas, a partir da recriação das experiências. Assim sendo, as narrativas orais são fontes inesgotáveis, uma vez que as entrevistadas retomaram momentos vivenciados ou não, de acordo com sua concepção de mundo, mas sem abandonar a concepção de mundo através do olhar do outro.

\section{AS ETAPAS DA PESQUISA}

As etapas da pesquisa, do tipo qualitativa e de cunho etnográfico, foram construídas no período de janeiro de 2013 a novembro de 2014, conforme descrição abaixo:

A primeira etapa da pesquisa foi desenvolvida logo após a escolha do tema. Foram realizadas a seleção e a leitura analítica de uma vasta bibliografia, análise documental e visualização de fotografias acerca da história da criação e do desenvolvimento do município de Guajará-Mirim e do Estado de Rondônia; da história dos seringais da Amazônia e da criação da RESEX Rio Ouro Preto. Além disso, também foram realizadas a leitura de obras sobre as temáticas: linguagem, cultura, memória, identidade e a função social das mulheres nos seringais. Os conteúdos mais relevantes foram organizados em forma de fichamentos.

$\mathrm{Na}$ segunda etapa, concluiu-se as primeiras leituras e a produção do projeto de pesquisa. Nesse momento, a fim de realizar visitas às comunidades, conforme requeria o projeto, providenciou-se a aquisição de itens indispensáveis para 
a realização da viagem e da estadia na reserva, tais como: gasolina para motor do barco, lanterna, barraca, colchonete, fogão pequeno, botija, gêneros alimentícios, de higiene e limpeza, kit de primeiros socorros, utensílios de cozinha, dentre outros. Para tanto, foram realizadas duas viagens.

Vale ressaltar que a primeira viagem foi feita até a comunidade Encrenca, na Reserva Extrativista do Pacaás Novos, em janeiro de 2013, na companhia da equipe da Secretaria de Estado do Desenvolvimento Ambiental (SEDAM) que tinha a frente o Diretor Sr. Adão Quintão e, na ocasião, foram realizadas entrevistas com três mulheres. A segunda viagem foi realizada em janeiro de 2014 e teve a duração de doze dias. $\mathrm{Na}$ ocasião, realizou-se visitas às comunidades do Alto Rio Ouro Preto. Na oportunidade, foram entrevistadas onze mulheres e oito homens.

Para um bom registro da linguagem e das narrativas orais para identificar os modos de vida das mulheres entrevistadas, foram adquiridos os seguintes materiais: gravador de voz, celular com câmera digital para fotografar e filmar, caneta, lápis, borracha, apontador, caderno, pendrive e computador portátil. Esses detalhes são importantes, pois no momento da pesquisa in loco, é essencial que não falte nenhum recurso que impeça ou dificulte o contato com o informante, pois toda atenção deve estar voltada para o objeto de estudo. Vale ressaltar que todos os recursos materiais e humanos foram custeados pelos próprios pesquisadores.
As participantes da pesquisa foram mulheres que vivem na RESEX do Rio Ouro Preto e para a realização da pesquisa foi necessário solicitar junto à ASROP uma permissão para adentrar na reserva. Considerando a dificuldade de acesso nas referidas comunidades, o Presidente da associação da ASROP, Sr. José Avilhaneda Amutari, se dispôs a ser o guia logístico durante a viagem. Na oportunidade, foram realizados a observação dos modos de vida dos moradores da RESEX, os registros fotográficos e a gravação das entrevistas, com a utilização das seguintes técnicas: diálogos assimétricos, conversações naturais e gravações de narrativas orais, que "[...] possibilita entender os contextos em que os sujeitos inseridos, e os consideramos como operadores de diferenças" (Tedeschi 2009: 182). Foram realizados, ainda, registros fotográficos e de áudio e vídeo.

$\mathrm{Na}$ terceira etapa, os dados coletados foram registrados e analisados à luz dos pressupostos teóricos e metodológicos dos estudos da História Oral, propostos por Delgado (2006); da Sociolinguística Varacionista, proposta por Mollica (2003), que apresenta os fatores internos/externos da variação linguística; dos Estudos Culturais Amazônicos, propostos por Loureiro (1995-1998) e outros.

$\mathrm{Na}$ quarta etapa, a partir das reflexões acerca do referencial teórico metodológico e da análise dos dados, concluiu-se a pesquisa, estruturando-a nesse artigo científico. 
A IMPORTÂNCIA SOCIAL DAS MULHERES NOS SERINGAIS DA AMAZÔNIA

Conforme as palavras de Beauvoir (1949), estas questões que discutem a posição de inferioridade da mulher na sociedade estão longe de serem novas. A autora ressalta que "O lugar da mulher na sociedade é sempre eles que estabelecem [...] A vontade masculina de expansão e domínio transformou a incapacidade masculina em maldição", pois o homem se constitui na posição de quem domina o Outro, ou seja, a mulher. Contudo, ao relembrar as palavras de Poulain de la Barre a autora adverte que "Tudo o que os homens escreveram sobre as mulheres deve ser suspeito, porque eles são, a um tempo, juiz e parte". (Beauvoir 1949:15-16) Neste contexto, embora, historicamente, haja um discurso sexista que classifica o homem como um ser mais destemido, corajoso e capaz de se arriscar em diferentes situações que oferecem perigo à vida ou à saúde para trabalhar em busca de sustento próprio ou de sua família, a mulher amazônica mostrou-se capaz de lidar com as adversidades e com diversas situações de risco e desconforto para atingir seus objetivos. Nesse sentido, cabe as palavras de Ferreira que diz: "[...] ainda é muito pequena a historiografia que trata sobre os papéis da mulher na empresa seringalista". (s/ano: 2) para mostrar que nos seringais da Amazônia, a mão de obra feminina teve valorosa significação para o desenvolvimento da região. As mulheres enfrentaram a mata fechada em jornadas duplas de trabalho para ajudar seus pais ou esposos e ainda para ajudar a criar os filhos. Se os esposos faleciam, as mulheres assumiam as frentes de trabalho nas "colocações", pois tinham que pagar as contas deixadas no "barracão" e, diante das adversidades e dos perigos da selva ou se submetiam a casamentos "arranjados", muitas vezes, pelo patrão, outras vezes, pelos familiares, visto que havia poucas mulheres nos seringais.

\section{SABERES E REPRESENTAÇõES DE MULHERES SERINGUEIRAS NA RE- SEX RIO OURO PRETO}

Conforme relatos das entrevistadas mais idosas, antigamente, as atividades exercidas pelas mulheres nos seringais eram realizadas obedecendo a necessidade de cada ocasião. O casal acordava ainda de madrugada por volta de uma hora da manhã, o marido saía às duas horas e a mulher saía cerca de uma hora depois, após de terminar alguns afazeres domésticos. Geralmente, um ia por uma "perna" da estrada e o outro pela outra "perna" que se encontravam na forma de um oito ou cada um ia para uma estrada diferente. Levavam consigo poronga na cabeça, a faca de seringa, uma vasilha com comida para o "quebra jejum" e o balde para colocar o leite; o marido levava também uma espingarda, voltavam no final da tarde com o leite e iam defumá-lo para transformá-lo nas chamadas "pélas", com aproximadamente 40 quilos.

Por volta da década de 1970, o processo de produção da borracha passou a ser realizado de outra forma: "com a borracha prensada, aí ficou melhor". Isso porque segundo a entrevistada, não era 
mais preciso sair às duas da manhã. $\mathrm{O}$ casal saía ao raiar do sol, cortavam a seringa e retornavam para a barraca próximo do meio dia. Depois de dois dias, eles voltavam àquela estrada quando o leite já havia coalhado, para retirar o cernambi. Assim, estavam todo dia numa estrada diferente. As tardes eram dedicadas ao acondicionamento do cernambi em caixas feitas de madeira. Essas caixas eram prensadas para que os pedaços de borracha se grudassem uns aos outros, formando assim um bloco de borracha com aproximadamente 40 quilos.

Com esse modo de produção, as famílias tinham mais tempo para se dedicarem também ao plantio de mandioca, por exemplo, e de outros produtos que complementavam a alimentação. Mesmo com essa jornada de trabalho excessiva, as mulheres ainda se dedicavam à preparação de remédios caseiros, chás, bolo de macaxeira e na produção do leite de castanha. Além disso, ainda cuidavam de todos os afazeres domésticos. Quando a mulher de um seringueiro ficava grávida, sempre era ajudada pela mulher de outro seringueiro na hora do parto. Esse era um momento festivo, com direito a uma fogueira no terreiro e "contação de causos assombrosos", mas ao mesmo tempo divertidos, pois nos seringais os momentos de lazer eram raros.

De acordo com observações feitas nas comunidades visitadas, atualmente, há pouca produção de borracha na RESEX Ouro Preto. As famílias não querem mais "cortar" seringa porque o preço da borracha não compensa o esforço depreendido nessa árdua tare- fa. Por isso, as famílias apostam, prioritariamente, na plantação da mandioca para a produção da farinha e também na coleta da castanha.

Nessas atividades, a mão de obra feminina é bem efetiva, pois as mulheres ajudam a roçar, plantar, tirar a macaxeira, colocar de molho, descascar, colocar a macaxeira na prensa e peneirar a massa. Geralmente, o serviço de torrar a farinha é executado pelos homens. Fato que pode ser facilmente entendido, visto que é realizado por volta das dez horas da manhã, horário em que a mulher está preparando o almoço.

$\mathrm{Na}$ coleta de castanha, as mulheres seringueiras também vão para o pique de castanha, às vezes toda família ou até mais de uma família, se deslocam para outro lugar que tenha uma concentração maior de castanheiras, numa espécie de acampamento improvisado, que eles chamam de tapiri. Eles permanecem no local em média uma semana, em meio à mata fechada. Assim que amanhece, homens, meninos e mulheres adultas, saem em busca da castanha. As meninas ficam no tapiri para cuidar das crianças menores e preparar a refeição. $\mathrm{Na}$ ocasião da pesquisa, a Entrevistada "H" (por questões éticas as entrevistadas serão denominadas por letras do alfabeto), mesmo no sétimo mês de gestação foi para o pique de castanha e trouxe uma lata de castanha na cabeça, o equivalente a dezoito "litros" como elas se referem.

Vale ressaltar que, na RESEX, atualmente, há moradoras idosas que, geralmente, já estão aposentadas, mas não querem morar na cidade. Então, por já 
não terem forças físicas para trabalhar na roça terceirizam o serviço. Ou seja: pagam para que alguém faça todo o serviço de plantio e colheita da macaxeira e quando a farinha é vendida elas pagam pelo serviço prestado. Nesse sentido, ressaltamos que os saberes, as práticas e os modos de vida dessas mulheres evidenciam que elas desempenham, ainda, um papel social relevante para a preservação da cultura e da identidade nos seringais da Amazônia rondoniense.

\section{A CASA TRADICIONAL DA MULHER SERINGUEIRA}

As primeiras moradias construídas nas colocações do seringal do Rio Ouro Preto eram chamadas de tapiris. Geralmente, o seringueiro vivia sozinho, e às vezes na companhia de outro seringueiro, quando não havia uma colocação para ele ou a demanda de leite era boa e o seringueiro "dono" da colocação precisava de ajuda para coletar o látex.

Com o passar do tempo, eles começaram a construir barracas. Segundo Neves (2007:35), "O seringueiro também era, em certa medida um nômade, mudava-se de um lugar para outro em busca de uma estrada boa de leite ou de um patrão que não explorasse tanto".

Somente no Segundo Ciclo da Borracha é que os seringalistas passaram a permitir, de forma pacífica, a entrada de mulheres nos seringais para evitar que os seringueiros abandonassem as colocações. "E o seringal deixa de ser um acampamento só de homens", con- forme afirma Nascimento (1996:4). A presença feminina contribuiu para a fixação do seringueiro nas colocações, pois era a mulher que enfeitava a casa, construía o fogão à lenha, limpava o terreiro e preparava as refeições com zelo, deixando a casa mais bonita e confortável.

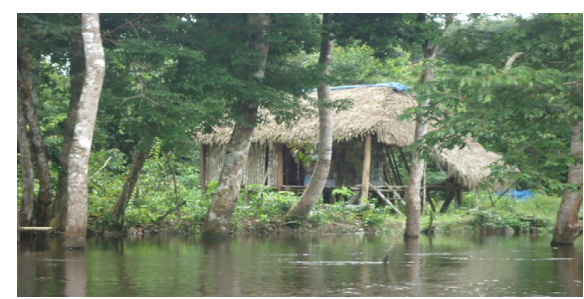

Figura 2 - Modelo de casa "tradicional" no Rio Ouro Preto/RO. Fonte: ALVES, Eva da Silva, 2014.

Assim sendo, após a participação da mulher no contexto do seringal, a casa do seringueiro ganhou um aspecto de morada definitiva. Nesse contexto, Neves (2007) menciona os estudos de Campello (1997), referentes a Lina Bo Bardi, que veio para o Brasil em 1946, afirmando que: "[...] toda casa, por mais simples que seja, deve ser digna de atenção, que as soluções dadas pela gente simples contêm uma sabedoria milenar" (2007:27). Essas pessoas, em sua maioria, nunca haviam morado em meio a matas tão fechadas, distante da família, longe de recurso médico-hospitalar e muitos outros "confortos" que a cidade pode oferecer, aprenderam a retirar da floresta alimento, medicamento e construíram uma nova história.

\section{A MULHER AGROEXTRATIVISTA}

O cenário dentro da RESEX Ouro Preto mudou ao longo dos anos. Atu- 
almente, as mulheres que residem na reserva não são conhecidas como "as mulheres dos seringueiros", mas como as mulheres agroextrativistas. A maioria delas não está mais envolvida apenas com a coleta do látex, pois se dedicam também ao plantio de outras culturas agrícolas. Além disso, algumas mulheres confeccionam artesanatos e produzem doces com produtos retirados da floresta como o coco babaçu e o cupuaçu.

Preocupadas com a educação dos filhos, algumas mulheres se dividem entre a cidade e a RESEX. Elas passam um tempo na reserva cuidando do plantio da mandioca e da coleta de castanha e depois vão à cidade para acompanhar a vida escolar dos filhos e visitá-los. Elas também se envolvem nas reuniões das Associações de Seringueiros e acompanham os movimentos em prol de benefícios para as comunidades.

A situação financeira das mulheres que vivem na RESEX também passou por modificações, uma vez que, o governo tem programas que beneficiam as mulheres agroextrativistas, como o Bolsa Escola, Bolsa Família, o Bolsa Verde, o Salário Maternidade e outros. Com isso, elas podem assumir, novamente, papeis fundamentais no sustento da família e ainda na vida escolar de seus filhos, pois além do dinheiro ganho com a venda da produção da farinha, da coleta da castanha e da extração do látex, elas podem contar com os recursos financeiros advindos desses benefícios.

\section{A CASA DA MULHER AGROEXTRA- TIVISTA}

Com a implantação, a partir de 1992, do Plano Agropecuário e Florestal de Rondônia (PLANAFORO), ocorreu uma mudança significativa na construção das moradias das comunidades da RESEX Rio Ouro Preto, pois o governo do Estado de Rondônia financiou a construção de casas em todas as comunidades. A madeira utilizada na edificação das moradias foi retirada da própria reserva, os demais materiais foram trazidos da cidade e a mão de obra ficou a cargo dos moradores das comunidades, que também receberam ajuda de custo pelos dias trabalhados.

Atualmente, a maioria das casas das mulheres agroextrativistas e de suas famílias são feitas de madeira serrada, coberta com telha e muitas possuem fogão a gás, gerador de energia, televisor e até mesmo 1antena parabólica. Porém, continuam sendo construídas com piso do tipo assoalho alto, devido às enchentes que ocorrem periodicamente.

Além disso, elas mantiveram o jirau e, na maioria das casas, ainda há o fogão à lenha. As mulheres também conservam a cozinha anexada à sala ampla e com parapeito. Ou seja, uma cozinha com espaço de igual tamanho que chamam de sala.

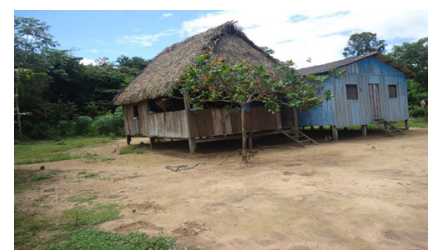

Figura 3 - Modelo de casa "moderna" no Rio Ouro Preto. Fonte: ALVES, Eva da Silva, 2014. 
É interessante observar que a parte de casa que mais se manteve nos moldes da casa do período do Segundo Ciclo da Borracha foi a cozinha/sala, que muitas vezes ainda é feita e coberta de palha. Assim sendo, a partir dos aspectos acima descritos, podemos afirmar que as marcas identitárias permaneceram nitidamente na arquitetura da casa ribeirinha/seringueira e que os valores culturais dessa comunidade estão agregados ao seu modo de vida.

\section{APRESENTAÇÃO E ANÁLISE DOS RESULTADOS DAS ENTREVISTAS}

A partir das reflexões do poeta Octávio Paz, Loureiro (1995) discute sobre a cultura amazônica, destacando o imaginário poetizante e estetizador das florestas e rios afirmando que a subjetividade do caboclo amazônico é influenciada pelo convívio evanescente com esse cenário "A cultura de um povo é fonte inesgotável de inspiração, de símbolos, de experiências, de trabalho acumulado, de beleza, de utopias e a preservação da memória coletiva por um grupo, ainda que seja pequeno é uma verdadeira tábua de salvação para toda a comunidade". (1995:77).

Nesse contexto, dentre os aspectos priorizados nas entrevistas com as mulheres seringueiras e agroextrativistas focalizou-se as seguintes temáticas: o trabalho na floresta; a relação com a família e com a natureza; elementos de misticismo e de subjetividade; aspectos lexicais específicos do contexto dos seringais.

\section{O TRABALHO NA FLORESTA}

$\mathrm{Na}$ concepção de Loureiro (1995:27) as práticas e os saberes das populações rurais-ribeirinhas são influenciadas pela cultura amazônica que segundo ele é " [...] produto de uma acumulação cultural que absorveu e se amalgamou com a cultura dos nordestinos que, em épocas diversas, mas especialmente no período da borracha, migraram para a Amazônia".

Contudo, embora as mulheres comentem sobre os benefícios de viver na floresta, elas não demonstram consciência sobre a função social muito importante que desempenharam ao longo dos anos no contexto dos seringais. Em seus discursos, a maioria evidencia um processo de negação da relevância de seus esforços no trabalho com a seringa. Esse aspecto pode ser verificado nas respostas abaixo:

Questão 1: A senhora ajudava o seu esposo na extração do látex para a produção da borracha?

"Não, nunca ajudei, eu só ajudo assim ele lavar o cernanbi pra imprensar, fazer a borracha, né! Mas agora quem corta é ele que eu não sei cortá [...]. Já fui colher o leite também." (Entrevis$\operatorname{tada} \mathrm{B})$.

“Não eu não ia não [...] só quando ele ia às vezes tirá o cualho, que ele cortava e deixava o leite, o leite no mato, né. Quando cualhava que tinha muito cualho e borrava ele pedia pra eu da uma ajuda, aí eu trazia um bucado daquele cualho dentro do saco, ele trazia um saco eu trazia outro.” (Entrevistada C). 
Conforme Tedeschi (2009:191), “[...] o trabalho produtivo feminino não é reconhecido pela sociedade como mão de obra produtiva, e sim como 'ajuda' ao trabalhador principal, o homem." Sobre esse aspecto, afirmamos que apesar do processo de negação evidenciado nos discursos das entrevistadas, identificamos no fragmento acima que as mesmas participavam ativamente das atividades de produção de borracha e farinha. Há também elementos que demonstram a falta de credibilidade dessas mulheres nas funções que desempenhavam nos seringais. Esse aspecto pode ser resquício da cultura machista que ainda prevalece nas comunidades rurais-ribeirinhas.

Questão 2: Quais atividades a senhora realizou ao longo da sua vida na Reserva?

"Só cuidano em filho, trabalhano, só. Agora não porque eu já sou aposentada eu já ajudo comprá o ranchinho pra dentro de casa, mas logo no começo só era trabano e cuidando dos filho, roçano só. [...] roçava e arrancava mandioca pra faze farinha pra ajudá ele, né." (Informante $\mathrm{C}$ ).

A entrevistada acredita que somente agora, depois de aposentada, é que realmente contribui com as despesas da casa. O que se explica pelo fato de que embora a mulher "ajudasse" o marido no trabalho diário era ele quem negociava a produção seja com o marreteiro, no barracão ou na cidade e, assim, a ela nunca era designado nenhum tipo de remuneração em dinheiro, pois o marido somente lhe dava bens de uso e consumo, como vestimenta e alimentação.

No relato da entrevistada " $A$ ", abaixo, ela também utiliza a palavra "só", que remete ao menosprezo pelo próprio esforço, pois se considerarmos as atividades por ela descritas, veremos que, além do trabalho com a produção da farinha, ela ainda tem que cuidar do filho, da casa, dos animais domésticos e do marido. "Da roça que eu faço, só é plantar e quando vai fazer farinha, boto macaxeira de molho que eu vou ajudar a tirar e penerar, só esse aí o meu serviço, agora arrancar e carregar isso aí eu num faço não.” (Entrevistada A).

Para Simonian (2001:97), assim como se pode perceber nos relatos das entrevistas, "a invisibilidade e a tentativas de silêncio e negação não se colocam como problemas para as mulheres", no entanto, a desvalorização dos trabalhos realizados, consequentemente, as tornam vulneráveis a discriminações, explorações e opressões.

A partir dos estudos de Tedeschi (2010) mostramos que a reconstituição das narrativas orais e histórias de vida coletadas in loco como a categoria gênero "[...] possibilita entender os contextos em que os sujeitos estão inseridos, e os consideramos como operadores de diferenças" (2010: 178). Dessa forma, afirmamos que a memória é constituída e estruturada pelos papeis sociais desempenhados pelos sujeitos nos diferentes contextos socioculturais nos quais eles interagem. 
Questão 3: A borracha defumada a senhora já fez? Como é que faz?

"Foi a primeira borracha que nos fizemo. A difumada você colhia, né, aí você aquecia o leite no fogo lento pro leite ficar grosso, pra você banha, você botava, vamo supor: eu corto hoje, pra mim fazer o princípio, né, corto hoje boto pra cualha dez vinte litro de leite, deixa cualha aquilo alí do tamanho do princípio que você quise fazer. Aí você corta uma tira assim de borracha, aí enrola num pau que chamava cavador, enrola, enrola, enrola, até o principio ficar dessa grossura (gestos) [...] Aí vai banhando, banhando, até fica do tamanho que você quiser." (Entrevistada D)

Destacamos que ao relembrar as atividades realizadas durante a produção da borracha, a Entrevistada 'D', descreve com detalhes todas as funções desempenhadas. No entanto, ao relatar os fatos, a mesma utiliza a terceira pessoa do discurso. Ou seja, relata de maneira impessoal.

Questão 4: Tem uma diferença de preço entre borracha que é defumada e a que é prensada?

"Menina, eu acho que não. $\mathrm{Na}$ época a gente vendia a borracha defumada no valor... Porque os patrão, tu sabe como é que era! Os patrão só queria mais é explorar os coitado do seringueiro. Vários dele que fazia de cinco tonelada de borracha, mas quanto, quanto nos num perdimo? [...] na época os patrão enganava muito, meu irmão num sabia lê, coitado!" (Entrevistada D)
A reconstituição das memórias das mulheres que vivem no contexto dos seringais está permeada por fatores sócio-históricos que refletem as dificuldades por elas enfrentadas. A mulher trabalhava, mas sua voz representativa (o homem), era por muitas vezes, vítima da opressão e era enganado, o que, de maneira geral, só piorava a sobrevivência de sua família.

\section{A RELAÇÃo COM A família e COM A NATUREZA}

Questão 1: Quando algum de seus filhos adoecia, como a senhora fazia para tratar a doença?

"Mandava, comprava um calmante no barracão com o patrão, graças a Deus que nunca foi muito doente meus filhos. [...] fazia chá pra dor de barriga, fazia chá de azeitona, fazia chá de... uma folha que tem no mato chamada escada de jaboti, hortelãzinho." (Entrevistada “F”).

O fragmento acima demonstra que as mulheres seringueiras utilizavam-se dos produtos da floresta para a produção de medicamentos. O contexto rural-ribeirinho favorece a construção desses conhecimentos, pois nas referidas regiões o acesso à medicina convencional é muito difícil, devido ao isolamento. Destacamos que essa herança cultural é repassada de geração em geração, através do conhecimento empírico, muito valorizado entre povos de comunidades tradicionais. 


\section{ELEMENTOS DE MISTICISMO E SUB- JETIVIDADE}

Na concepção de Loureiro (1995:56), "A cultura do homem ribeirinho é fruto de um imaginário que se reflete nos mitos e o ambiente onde ele vive the proporciona uma característica peculiar". Abaixo, transcrevemos um fragmento da narrativa da Entrevistada "F", que demonstra que o contexto rural-ribeirinho favorece o imaginário da mulher seringueira, traçando aspectos subjetivos à cultura amazônica:

"Aí, nós morava no seringal aqui mesmo em Rondônia. Aqui no Querequeter. Ai, a mãe tava de resguardo mandou eu buscar água na beira do Azul um garapé grande que tem. Aí, eu fui buscar água, cheguei lá, eu gostava muito de pegar pexinho, que tava meio seco o garapé. Aí, eu vi tá banzerando, que eu olhei, era o Cabeça de Cuia que já vinha pra me pegar. Ele é um homem, ele é cego dum olho, a cabeça pelada e ele vinha com água até nos peito, chega ele vinha rindo. Aí, eu gritei e subi o barranco correno, quase matei a mãe de resguardo. Aí, eu me lembro, eu tinha sete anos de idade". (Entrevistada "F").

Sobre esse aspecto, Loureiro afirma que o imaginário é um importante elemento constituidor da identidade. Assim, a partir das narrativas orais e da reconstituição das memórias, as mulheres seringueiras demonstram suas práticas, seus saberes, suas crenças e evidenciam marcas identitárias tipicamente amazônicas. Observa-se no relato desta memória que o território, o local, é de suma importância para garantir a sobrevivência e manutenção das condições adequadas para a existências de elementos socioculturais de uma comunidade. Uma vez que é em torno do território, suas nuances, curvas, recursos e imaginário que a comunidade se constituí, se refaz e são constituídas as representações sociais, de gênero e se forma o misticismo e a subjetividade das relações dos membros da comunidade.

\section{ASPECTOS SEMÂNTICO-LEXICAIS ESPECÍFICOS DO CONTEXTO DOS SERINGAIS}

De acordo com Dubois (2001: 364) o léxico é: "Um conjunto das unidades que formam a língua de uma comunidade, de uma atividade humana, de um locutor etc." Nesse sentido, o léxico reflete as marcas identitárias linguísticas, pois de acordo com Loureiro: "A cultura do homem ribeirinho é fruto de um imaginário que [...] lhe proporciona uma característica peculiar. Por estar fora da zona urbana e de tudo o que caracteriza a vida nas grandes cidades [...]." (1995: 56).

A partir da linguagem, tipicamente ribeirinha, essas mulheres demonstram suas práticas, seus saberes, suas crenças. Esse contexto favorece o imaginário das mulheres seringueiras e agroextrativistas, traçando aspectos subjetivos à cultura amazônica. Sobre esse aspecto, Loureiro (1995: 75) afirma também que: "É possível identificar-se na cultura amazônica um imaginário poetizante e estetizador governando o sistema de funções culturais, tendo como suporte material a natureza e desenvolvendo-se 
através da vaga atitude contemplativa própria do homem da região em sua imersão no devaneio."

Além dos aspectos semântico-lexicais, identificamos na fala das mulheres seringueiras e agroextrativistas alguns processos morfossintáticos distintos. Dentre eles, destacamos um fragmento do diálogo entre a pesquisadora e a Entrevistada " $A$ ": Então ela (a mãe) era seringueira de fato? A entrevistada responde: "É, seringueira de fato", nota-se uma topicalização do sujeito, se analisando a oração fora do contexto, embora haja um predicativo, não se pode identificar o sujeito e assim a marca a impessoalidade do discurso.

\section{CONSIDERAÇÕES FINAIS}

O objetivo geral desse trabalho foi registrar, descrever e analisar, à luz dos estudos sociolinguísticos e culturais, elementos constituidores da linguagem, da cultura e da identidade, evidenciados nas narrativas orais e nas histórias de vida de mulheres seringueiras da RESEX Rio Ouro Preto/RO.

A partir da reconstituição das memórias foi possível identificar alguns saberes, modos de vida, subjetividade e misticismo nas narrativas orais das mulheres seringueiras da RESEX Rio Ouro Preto. Também foi possível refletir sobre os sentidos dos fatos históricos e sociais narrados pelas mulheres seringueiras.

Identificou-se, a partir do registro das histórias de vida, que essas mulheres contribuíram significativamente para a preservação da história, da cultura e da identidade feminina na referida reserva, pois elas desempenharam um papel social muito importante na constituição dos seringais.

Constatamos, a partir da pesquisa in loco que as referidas comunidades passaram por importantes transformações ao longo dos anos, principalmente em relação aos aspectos de moradia, acesso às comunidades e organização social. O processo comunicativo, os modos de produção da borracha, o acesso à educação e à saúde também foram favorecidos com o surgimento de novas tecnologias.

As mulheres seringueiras mais idosas evidenciam, ainda, um discurso permeado por elementos que demonstram a submissão e a degradação social da mulher imposta pela cultura machista e mostram um certo conformismo com a sua posição social. Constatou-se que essas mulheres sequer percebem a relevância de seus esforços como mãe, esposa, e, sobretudo, no papel inegável como provedora de alimentos. Ao reviver suas práticas, através narrativas acerca dos tempos em que arriscavam durante as madrugadas em estradas de seringa, mesmo ao dizer que assumiram suas famílias, após o falecimento elas não são capazes de dizer em primeira pessoa: eu era, eu sou, eu fui seringueira, pois expressam um discurso submisso, oprimido.

Quanto às mulheres seringueiras e extrativistas mais jovens, observou-se que elas demonstram, mesmo que timidamente, vários conhecimentos sobre seus direitos e estão organizadas politicamente, pois mesmo traba- 
lhando na extração do látex, coleta da castanha ou na produção da farinha, a mulher continuou com seus afazeres domésticos, mas na história elas não dividiram o título de seringueiras com os maridos. Identificou-se, também, na pesquisa in loco, que apesar dos avanços, os poderes públicos constituídos ainda não reconhecem a função da mulher como seringueira nas estruturas dos seringais, pois embora elas trabalhem arduamente nas colocações e estradas de seringa, essas mulheres ainda não são reconhecidas como seringueiras, apenas como ajudadoras dos maridos, considerados os 'verdadeiros' seringueiros.

De modo geral, as mulheres seringueiras da RESEX do Rio Ouro Preto evidenciam que o discurso por elas produzido está permeado por elementos que demonstram a submissão dessas mulheres, que por terem vivido grande parte da vida no contexto dos seringais, foram moldadas a uma cultura patriarcal, onde o homem é o detentor do poder, da força e da coragem e que, portanto, deve ser destinados a eles os méritos pelas conquistas mais árduas realizadas durante o período em que lutaram pela sobrevivência nos seringais. Nesse sentido é possível compreender as relações de gêneros que ocorrem na comunidade, onde a mulher é incapaz de perguntar ao marido porque ele ao receber a visita de um outro seringueiro, por exemplo, mostra a borracha, a farinha produzida, a castanha coletada, mas não diz que teve a valorosa ajuda de sua companheira.

Por outro lado, verificamos que a mulher seringueira evita dizer à outra mulher que trabalha com tarefas tão árduas, talvez por vergonha de admitir que exerce um trabalho onde segundo a cultura dos seringais, deveria ser realizada somente pelos homens. Essa é outra questão que advém da cultura machista, na qual o homem deve ser o provedor de sua família, enquanto a mulher deve cuidar dos filhos e da casa.

Portanto, a partir das histórias registradas, pode-se concluir que a linguagem das mulheres seringueiras reflete, de forma peculiar, suas marcas identitárias linguísticas e socioculturais, expressando subjetividades e saberes singulares.

\section{REFERÊNCIAS}

Benchimol, S. 1977. Amazônia: um poucoantes e além - depois. Manaus: Ed. Umberto Calderaro, 1977.

Brasil. Lei 11.904, de 14 jan. 2009. Diário Oficial [da] República Federativa do Brasil, Poder Executivo, Brasília, DF, 15 jan. 2009. Seção 1, p. 1. Disponível em: < $\underline{\text { http:// }}$ www.planalto.gov.br/ccivil 03/ Ato20072010/2009/Lei/L11904.htm> Acesso em 27 mar de 2017.

Beauvoir, S. 1980. O segundo Sexo: Fatos e Mitos. Rio de Janeiro: Ed. Nova Fronteira.

Confalonieri, U.E.C. 2005. Saúde na Amazônia: Um modelo conceitual para análise de paisagens e doenças. Estudos Avançados 19(53):221-236.

Cruz, T. A.; M. Montysuma 2008. Perspectivas de gênero acerca de experiências cotidianas no seringal Cachoeira - Acre (1964-2006). Revista História 12(3):219-236 Cunha, E. da. 1967. À margem da história. São Paulo: Editora Lello Brasileira S/A. 
Delgado, L. A. N. 2006. História oral: memória, tempo, identidades. Belo Horizonte: Autêntica.

Derickx, J. 2007. Reserva extrativista: mais vida neste chão. Belém: Meridional.

Djalma, B. 2006. Amarônia - Cultura e Sociedade. Manaus: Valer.

Ferreira, M. L. F. 2014. Mulheres no seringal: submissão, resistências, saberes e práticas (19401945). Disponível em: < http://www.uel. br/grupo-estudo/processoscivilizadores/ portugues/sitesanais/anas $8 / \operatorname{artigos} / \mathrm{Ma}-$ riaLiegeFreitasFerreira.pdf $>$ Acesso em: 10/03/2016.

Hardenburg, W. 2016. The Putumayo: The Devil's Paradise. Traduzido por Hélio Rocha. São Carlos.

ICMBIO. 2014. Plano de Manejo da Resex do Rio Ouro Preto.

Leal, D. A. 2013. Direitos e processos diferenciados de territorialização: os conflitos pelo uso dos recursos naturais no rio $\mathrm{Ma}-$ deira (1861-1932). Tese de Doutorado. Instituto de Ciências Humanas e Letras. Programa de Pós-Graduação em Sociedade e Cultura na Amazônia. Manaus: UFAM.

Loureiro, J. J. P. 1995. Cultura Amazônica: uma poética do imaginário. Belém: CEJUP.

Meireles, D. M. 1989. Guardiães da Fronteira Rio Guaporé, século XVIII. Petrópolis: Vozes.

Mollica, M. C.; M. L. Braga. 2012. Introdução à Sociolinguistica: o tratamento da variação. São Paulo: Contexto.

Moret, A. 2004. Relatório do levantamento Sócio - Econômico da Reserva Extrativista do Rio Ouro Preto (ASAEX) - Guajará-Mirim. Universidade Federal de Rondônia.

Moser, L. M. et. al.2014. Museu Histórico Municipal de Guajará-Mirim, seu idealizador e fundador. Revista Veredas Amazônicas 3(1):1-11.
Nascimento, M. G. 1996. O espaço Ribeirinho: migrações nordestinas para os seringais da Amazônia. Dissertação de Mestrado. Faculdade de Filosofia, Letras e Ciências Humanas-DG/USP. São Paulo: mimeo.

Neves, M. C. O. 2007. A colocação e a casa de seringueiro: Exemplo de arquitetura vernácula da Amazônia. Rio Branco: Gráfica TJ/AC.

Oliveira, M. C. 2013. Arte Rupestre em Rondônia. Presidente Medici.

Santos, N. 2014. Seringueiros da Amazônia: sobreviventes da fartura. Curitiba: Appris.

Simonian, L. T. L. 2001. Mulheres seringueiras na Amazônia brasileira: trabalho duro, silenciado e quase extinto, in Mulheres da Floresta amazônica - entre o trabalho e a cultura. Belém: Editora do NAEA. p. 69-103. [Fotografias].

Tedeschi, L. A. 2009. Limites de gênero, limites do mundo: memórias de mulheres agricultoras e a luta por direitos sociais. Revista História Oral 12(1-2):177-206.

Teixeira, M. A. D.; D. R. Fonseca. 2003. História Regional: Rondônia. 2 ed. Porto Velho: Rondoniana.

Wolff, C. S. 2011. Mulheres da floresta: outras tantas histórias. Revista de Estudos Amazônicos VI(1):21-40. 